\title{
Assessingthe Kinesiophobia and Depression Status at Return to Sport Following Sport Related Injuries in Contact and Non-Contact Sports
}

\section{Fiziksel Temas İçeren ve İçermeyen Sporlarda Yaralanma Sonrası Spora Dönüşte Kinezyofobi ve Depresyon Düzeylerinin İncelenmesi}

\author{
Celil Kaçoğlu ${ }^{1}$, Erdem Atalay², Begümhan Turhan ${ }^{3}$ \\ ${ }^{1}$ Coaching Education Department, Faculty of Sport Sciences, Anadolu University, Eskişehir, Turkey \\ ${ }^{2}$ Sports Medicine Department, Yunus Emre State Hospital, Eskişehir, Turkey \\ 3Physical Therapy and Rehabilitation Department, Faculty of Health Sciences, Hasan Kalyoncu University, Gaziantep, \\ Turkey
}

C. Kaçoğlu it

0000-0002-1817-5234

E. Atalay

0000-0002-7749-7735

B. Turhan iD

0000-0003-0842-2059

Geliş Tarihi / Date Received: 18.11.2017

Kabul Tarihi / Date Accepted: 14.02.2018

Yayın Tarihi / Published Online: 26.04.2018

\section{Yazışma Adresi /}

Corresponding Author:

Begümhan Turhan

Hasan Kalyoncu Üniversitesi

Sağlık Bilimleri Fakültesi

Fizyoterapi ve Rehabilitasyon

Bölümü, Gaziantep, Turkey.

E-mail:

begum.aliosmanoglu@hku.edu.tr

(C)2018 Türkiye Spor Hekimleri Derneği. Tüm hakları saklıdır.

\section{ABSTRACT}

Objective: The aim of this study is to examine the levels of kinesophobia and depression following sports injuries in physically contact and non-contact sports.

Material and Methods: A total of 130 male athletes from 14 different sports, who were injured at least six months before were included in the study. Individuals participating in the study were interviewed by means of the Beck Depression Inventory and the Tampa Kinesiophobia Scale. Participants were also asked to complete a form to determine the injuries they had experienced.

Results: There were no statistically significant differences between the physically contact and non-contact sport groups' kinesiophobia and depression scores $(p>0.05)$. There was no significant correlation between these two scores $(r=0.27, p>0.05)$. Beck Depression Inventory scores following injuries that occurred in training and competition were significantly higher in physically contact sports than non-contact sports $(p<0.05$ and $p<0.001$, respectively).

Conclusion: Depression and kinesophobia scores following sport injuries were not significantly different for physically contact and non-contact sports. Kinesophobia is not related to the emotional status of athletes.

Keywords: Athletic injuries, return to sport, fear, depression

\section{öz}

Amaç: Bu çalışmanın amacı fiziksel temas içeren ve içermeyen sporlarda spor yaralanmasını izleyen süreçte kinezyofobi ve depresyon düzeylerini incelemektir.

Gereç ve Yöntem: Bu çalışmaya en az altı ay önce spor yaralanması geçirmiş 130 erkek sporcu dâhil edildi. Çalışmaya katılan sporcular, bire bir görüşme şeklinde Beck Depresyon Envanteri ve Tampa Kinezyofobi Ölçeği ile değerlendirildi. Ayrıca katılımcılardan geçirmiş oldukları yaralanmaya ilişkin bilgileri değerlendiren bir form doldurmaları istendi.

Bulgular: Fiziksel temas içeren ve fiziksel temas içermeyen sporlar arasında kinezyofobi ve depresyon skorları istatistiksel olarak anlamlı düzeyde farklılık göstermemektedir $(p>0.05)$. Depresyon skorları ile kinezyofobi skorları arasında korelasyon bulunmadı $(r=0.27)$. Antrenman ve müsabaka sırasında meydana gelen yaralanmalardan sonra belirlenen depresyon skorlarının 
fiziksel temas içeren sporlarda, fiziksel temas içermeyen sporlara göre anlamlı oranda yüksek olduğu bulundu (sırasıyla $\mathrm{p}<0.05$ ve $\mathrm{p}<0.001)$.

Sonuçlar: Spor yaralanmaları sonrası depresyon ve kinezyofobi skorlarının fiziksel temas içeren ve içermeyen sporlar arasında farklı olmadığı belirlendi. Kinezyofobinin sporcuların duygusal durumlarıyla ilişkili olmadığı söylenebilir.

Anahtar Sözcükler: Spor yaralanmaları, spora dönüş, korku, depresyon

Available at: http://journalofsportsmedicine.org and http://dx.doi.org/10.5152/tjsm.2018.092

Cite this article as: Kacoglu C, Atalay E, Turhan B. Assessing the kinesiophobia and depression status at return to sport following sport related injuries in physically contact and non-contact sports. Turk J Sports Med. 2018;53:67-75.

\section{GíRiș}

Spor yaralanmalarının ilk dönemlerinde en sık gözlenen psikolojik problem, duygu durum bozukluğudur. Spor yaralanmaları; stres, düşük benlik saygısı, depresyon, korku, öfke, bilinç bulanıklığı ve kaygı dâhil birçok olumsuz psikolojik duruma neden olabilmektedir (1-3). Spor yaralanmaları sonrası sporcunun içinde bulunduğu olumsuz psikolojik durum ve depresyon zaman içinde giderek azalma eğilimi göstermekle birlikte, spora başarılı bir şekilde dönüşte sporcunun verdiği psikolojik tepkilerin oldukça önemli bir etkiye sahip olduğu belirtilmektedir (4-6).

Pozitif psikolojik tepkiler, sporcuların yaralanma öncesi düzeylerine geri dönme olasılıklarını ve dönüş süresini olumlu etkilerken, korku ise spor yaralanmaları sonrasında sporcuların toparlanma ve rehabilitasyon sürecinde spora geri dönüşünü olumsuz yönde etkileyen duygusal bir tepkidir $(5,6)$. Ayrica, bir spor yaralanmasindan kaynaklanan ağrı durumunda da korku en dikkat çeken psikolojik faktörlerden biridir (7). Korku, acı ya da ağrı tehdidi gibi daha önceden deneyimlenen durumlara tepki olarak kaçma ve kaçınma özellikli davranışları tetikleyebilir. Kinezyofobi olarak isimlendirilen yeniden yaralanma korkusu, limbik sistem yapılarından amigdala ve insula bölgeleri ile bağlantılı bir korku çeşididir $(8,9)$.

Kori ve ark., kinezyofobiyi yaralanmaya duyarlılık ve kırılganlık inancindan kaynaklanan olumsuz etkilere sahip hareket ve aktivite korkusu olarak tanımlamışlardır (10). Hareket ve aktivite korkusu kavramlarının yanı sıra, yeniden yaralanma korkusu kavramı da kinezyofobi ile aynı anlamda kullanılmaktadır. Kinezyofobi, spor yaralanması sonrasında rehabilitasyon veya tedavi sonuçlarını olumsuz yönde etkileyebilmektedir (11). Bunun aksine, spora geri dönüş motivasyonu ve algısı ise spora geri dönüşü pozitif yönde etkileyen psikolojik faktörlerdendir (12).

Spor yaralanmalarının ortaya çıkışında iç ve/veya diş birtakım faktörler rol oynamaktadır. Spor dalıyla ilişkili dışsal faktörlerden biri yapılan sporun rakip oyuncuyla fiziksel temas içerip içermemesidir $(13,14)$. Spor ve rekreasyonel aktivite nedenli yaralanmalarda en büyük risk faktörü yapılan fiziksel aktivitenin doğasıdır ve fiziksel temas içeren (FTi) sporlar en yüksek riski taşırlar (15). FTİ sporlarda spor yaralanma oranları, fiziksel temas içermeyen (FTiM) sporlara göre daha yüksektir (16). Bu oran FTİ sporlarda \%13.2, FTiM sporlarda \%6.6 bulunmuştur (17).

Rehabilitasyon süreçlerinin iyi organize edilememesi veya klinik hedefleri tam anlamıyla yerine getirmeme gibi bazı nedenlerle de sporcularda sık sık aynı bölgelerde yaralanma meydana gelebilmektedir. $\mathrm{Bu}$ ve benzeri nedenlerden dolayı, yeniden yaralanma korkusu ile bazı sporcuların, spordan veya fiziksel aktiviteden kaçınma eğilimi gösterebildikleri belirtilse de (18); ulaşlabilen kaynaklarda, yapılan sporun doğasında bulunan fiziksel temasın kinezyofobiye ve depresyona etkilerine ilişkin verilere rastlanmadı.

FTİ veya FTIM sporlar yapan sporcularda, spor yaralanması sonrası kinezyofobi ve depresyon düzeylerinin belirlenmesi; yaralanmalardan korunma, yaralanma sonrası rehabilitasyon süreci ve spora geri dönüş konularında önemli katkılar sağlayabilecektir. Bu nedenle çalışmanın amacı, FTI ve FTIM sporlar yapan ve spor yaralanması geçirmiş sporcularda kineziyofobi ve depresyon 
düzeylerini incelemekti. Buna ek olarak, FTİ ve FTIMM sporlarda yaralanma sıklıklarını belirlemek, ayrıca meydana geldiği aktivite türleri ve sezon dönemleri ile ilişkilerini oransal olarak ortaya koymak amaçlandı.

\section{GEREÇ ve YÖNTEMLER}

$\mathrm{Bu}$ çalışmaya spor yaralanması tanısı konulmuş ve en az altı ay önce spor yaralanması geçirmiş, FTİ sporlar yapan 76 ve FTIM sporlar yapan 54 erkek sporcu olmak üzere 14 farkl spor dalından toplam 130 sporcu gönüllü olarak katıldı. Sporcuların yaş ortalamaları $24.0 \pm 6.0 y ı l$ (FTİ:26.0 \pm 1.1 , FTIM:23.0 \pm 2.7 ), boy ortalamalar1 $180.4 \pm 7.9 \mathrm{~cm} \quad$ (FTİ: $181.8 \pm 8.4 \quad \mathrm{~cm}$, FTİM:178.4 $\pm 6.8 \mathrm{~cm})$, vücut ağırlı̆̆ $77.9 \pm 12.9 \mathrm{~kg}$ (FTİ: $80.1 \pm 13.8 \mathrm{~kg}$, FTIM:74.8 \pm 11.0 $\mathrm{kg}$ ) idi. Katılımcıların haftalık antrenman süre ortalamaları $14.1 \pm 7.7$ saatti (FTI: $12.2 \pm 4.2$ saat, FTiM: $17.1 \pm 10.4$ saat).

Çalışmaya dâhil edilen spor dalları Amerikan Pediatri Akademisi, Spor Hekimliği ve Fitness Komitesinin fiziksel temas oranına göre yapmış oldukları sınıflama (19) göz önüne alınarak yapıldı ve dökümü Tablo 1'de belirtilmektedir.

Tablo 1. Çalışmaya dâhil edilen spor dalları

\begin{tabular}{ll}
\hline $\begin{array}{c}\text { Fiziksel temas içeren } \\
\text { sporlar }\end{array}$ & $\begin{array}{c}\text { Fiziksel temas } \\
\text { içermeyen sporlar }\end{array}$ \\
\hline Basketbol & Atletizm \\
Futbol & Badminton \\
Güreş & Masa tenisi \\
Hentbol & Yüzme \\
Rugby & Oryantiring \\
& Vücut geliştirme \\
& Kort tenisi \\
& Dans \\
& Bisiklet \\
\hline
\end{tabular}

Kadınlarda erkeklere göre spor yaralanması sonrası depresyon düzeyi daha yüksek olduğu için, ayrıca jimnastik haricinde kadın ve erkeklerin spor yaralanma oranları eşit olduğundan, bu çalışmaya sadece erkek sporcular dâhil edildi $(4,20,21)$.
Çalışmaya katılan bireyler birebir görüşme yoluyla Beck Depresyon Envanteri (BDE) ve Tampa Kinezyofobi Ölçeği (TKÖ) ile değerlendirildi. TKÖ, kas-iskelet sistemi ile ilişkili sağlık problemlerinde kullanılan 17 soruluk bir ölçektir. Ölçeğin güvenilirliği için yaralanmanın en az altı ay önce geçirilmiş olması gerekmektedir. Sporcu toplamda 17-68 arasında değişen bir skor almaktadır. Ölçekte kişinin aldığı puanın yüksek oluşu kinezyofobisinin de yüksek olduğu anlamına gelmektedir (22).

Bu çalışmada Türkçe geçerlilik ve güvenilirliğini Yılmaz ve ark.nın yapmış olduğu TKÖ anketi kullanıldı (23). Toplam puanın 37'den yüksek olması yüksek derecede kinezyofobi olarak değerlendirildi (24).

Katılımcıların depresyon düzeylerini değerlendirmek için de Türkçe geçerlilik ve güvenilirliğini Hisli'nin yapmış olduğu BDE kullanılmıştır. Envanter toplamda 21 sorudan oluşmaktadır. Her soru 0-3 puan arasındaki değerlerle puanlandırılmaktadır. Puan değeri arttıkça depresyon durumunun ağırlaştığı kabul edilmektedir (25).

Katılımclardan yaş, boy, vücut ağırlığı, spor geçmişleri, haftalık aktivite düzeyleri, haftalık antrenman sayısı ve süresi bilgilerini belirlemek için bir form doldurmaları istendi. Ayrıca bu formda yaralanma geçmişleriyle ilgili olarak, yaralanmayı ne kadar süre önce geçirdikleri, yaralanma döneminde uygulanan tedaviler, spordan ne kadar süre uzak kaldıkları gibi bilgiler de sorgulandı. Bu çalışma için Eskişehir Osmangazi Üniversitesi Girișimsel Olmayan Etik Kurulundan Etik kurul onayı alınmıștı (Karar no:80558721/G100).

\section{İstatistiksel Analiz}

İstatistiksel analiz için tek yönlü varyans analizi kullanıldı. Gruplar arası değişimin varlığı bağımsız örneklem T-testi ile değerlendirildi. Varyansların homojen olmadığı durumlarda farkın hangi ölçümden kaynaklandığını belirlemek amaciyla Games Howell post-hoc testi uygulandı. Aritmetik ortalama, frekans ve standart sapma değerleri hesaplandı. Anlamlılık düzeyi olarak $\mathrm{p}<0.05 \mathrm{kabul}$ edildi. Elde edilen 
veriler arasındaki ilişkiler Pearson Momentler Çarpımı korelasyon testi ile belirlendi. Korelasyon analizinde Pearson Correlation ifadesinin karşısında ifade edilen " $r$ " değerleri değerlendirildi.

\section{BULGULAR}

Katılımcıların spor geçmişi süreleri Tablo 2'de verilmiştir. Spor geçmişleri açısından gruplar arası incelendiğinde FTİ ve FTIMM sporları yapan sporcuların TKÖ ve BDE skorları arasında anlamlı bir fark bulunmamaktadır ( $\mathrm{p}>0.05)$.

Tablo 2. Sporcuların spor geçmişi sürelerine göre kinezyofobi ve depresyon düzeylerinin gruplar arası karşılaştırılması

\begin{tabular}{lccccccc}
\hline Spor Geçmişi & N & $\begin{array}{c}\text { FTí TKÖ } \\
\text { skorları }\end{array}$ & $\begin{array}{c}\text { FTiM TKÖ } \\
\text { skorları }\end{array}$ & p-değeri & $\begin{array}{c}\text { FTí BDE } \\
\text { skorları }\end{array}$ & $\begin{array}{c}\text { FTiM BDE } \\
\text { skorları }\end{array}$ & p-değeri \\
\hline $\mathbf{1 - 3}$ yıl & 10 & $36.8 \pm 8.9$ & $38.0 \pm 6.7$ & 0.56 & $3.80 \pm 3.85$ & $4.15 \pm 2.11$ & 0.12 \\
\hline $\mathbf{4 - 6}$ yıl & 35 & $33.4 \pm 7.1$ & $36.3 \pm 8.7$ & 0.45 & $5.65 \pm 8.02$ & $6.02 \pm 3.81$ & 0.47 \\
$\mathbf{7 - 9}$ yıl & 20 & $36.7 \pm 8.9$ & $39.7 \pm 9.1$ & 0.30 & $4.65 \pm 4.14$ & $3.87 \pm 3.65$ & 0.57 \\
\hline $\mathbf{9}$ yıl ve üstü & 65 & $37.2 \pm 7.0$ & $35.5 \pm 5.9$ & 0.12 & $6.12 \pm 5.87$ & $5.15 \pm 7.12$ & 0.88 \\
\hline
\end{tabular}

FTi: Fiziksel Temas İçeren, FTiM: Fiziksel Temas İçermeyen, TKÖ: Tampa Kinezyofobi Ölçeği, BDE: Beck Depresyon Ölçeği. Değerler ortalama \pm standart sapmadır. İstatistiksel anlamlılık düzeyi $\mathrm{p}<0.05$ anlamlı kabul edilmiştir.

FTI sporlar yapanlarda toplam TKÖ skorları ortalaması $36.4 \pm 7.4$, FTIM sporlar yapanlarda ise $36.7 \pm 7.7$ olarak hesaplandı. Her iki grubun toplam TKÖ puanları arasında istatistiksel olarak anlamlı düzeyde fark bulunmamaktadır $(\mathrm{p}=0.80)$. Sporcuların BDE bulguları $0-34$ aralığında puanlandırıldı. BDE skorlarına göre bireylerin ortalama değerleri depresyon bulgusu göstermemektedir. FTİ sporlarda BDE ortalaması $6.35 \pm 7.09$, FTIM sporlarda $4.51 \pm 4.42$ bulundu. Gruplar arasinda depresyon puanları açısından anlamlı bir farklılık bulunmamasına rağmen $(\mathrm{p}=0.95)$, FTİ sporlarda BDE skor ortalamalarının FTiM sporlara göre kısmen yüksek olduğu görülmektedir (Tablo 3). BDE skorları ile TKÖ skorları arasında korelasyon bulunmadi $(\mathrm{r}=0.27)$.

Tablo 3. Kinezyofobi ve depresyon düzeylerinin gruplar arası karşılaştırılması

\begin{tabular}{lccc}
\hline & $\begin{array}{c}\text { FTİ spor yapan } \\
\text { sporcular }\end{array}$ & $\begin{array}{c}\text { FTİM spor yapan } \\
\text { sporcular }\end{array}$ & p-değeri \\
\hline TKÖ skorları & $36.4 \pm 7.4$ & $36.7 \pm 7.7$ & 0.80 \\
BDE skorları & $6.35 \pm 7.09$ & $4.51 \pm 4.42$ & 0.95 \\
\hline
\end{tabular}

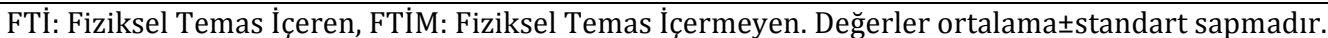
İstatistiksel anlamlılık düzeyi $\mathrm{p}<0.05$ anlamlı kabul edilmiştir.

Yaralanmanın geçirildiği aktivite türüne göre antrenman sırasında veya müsabaka sırasında geçirilen yaralanmalar açısından, FTİ sporlarda TKÖ skorları antrenman ya da müsabaka sırasında yaralanma geçirmeye bağlı olarak istatistiksel açıdan anlamlı bir farklılık göstermemektedir $(\mathrm{p}=0.94)$. Benzer şekilde, FTIM sporlarda da TKÖ skorları için antrenman ya da müsabaka sırasında yaralanma geçirmeye bağlı olarak istatistiksel açıdan fark yoktur $(p=0.33)$. Tablo 4'te de görülebileceği üzere, yaralanmanın antrenman ve müsabaka sırasında geçirilmesine bağlı olarak TKÖ skorlarında, FTİ ve FTIM sporlarda gruplar arası anlamlı bir fark bulunmamaktadır ( $\mathrm{p}>0.05)$. FTI sporlarda FTIM sporlara göre antrenman sırasında geçirilen yaralanmalardan sonra görülen BDE skorlarının anlamlı oranda daha 
yüksek olduğu $(\mathrm{p}<0.05)$, müsabaka sırasında geçirilen yaralanmalarda ise bu farkın daha belirgin olduğu bulundu ( $\mathrm{p}<0.001)$.
TKÖ ve BDE skorlarında yaralanmanın sezon öncesi, sezon içi ya da sezon sonrası geçirilmiş olması açısından FTİ ve FTIMM gruplar arası anlamlı bir fark gözlenmedi ( $p>0.05)$.

Tablo 4. Kinezyofobi ve depresyon düzeylerinin yaralanma geçirilen sezon dönemi ve aktivite türü açısından gruplar arası karşılaştırılması

\begin{tabular}{|c|c|c|c|c|c|c|c|c|c|}
\hline \multirow{4}{*}{ 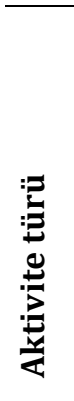 } & & \multicolumn{2}{|c|}{$\begin{array}{c}\text { Yaralanma } \\
\text { oranları (\%) }\end{array}$} & \multicolumn{2}{|c|}{ TKÖ skorları } & \multirow{2}{*}{ p-değeri } & \multicolumn{2}{|c|}{ BDE skorları } & \multirow{2}{*}{ p-değeri } \\
\hline & & FTİ & FTiM & FTí & FTiM & & FTi & FTiM & \\
\hline & Antrenman & 52.3 & 75.9 & $36.4 \pm 7.1$ & $36.6 \pm 6.9$ & 0.43 & $4.32 \pm 1.20$ & $3.21 \pm 1.00$ & $0.002^{*}$ \\
\hline & Müsabaka & 47.7 & 24.1 & $36.9 \pm 7.9$ & $37.4 \pm 8.5$ & 0.44 & $6.32 \pm 3.60$ & $3.96 \pm 2.60$ & $0.001^{* *}$ \\
\hline & Sezon öncesi & 18.4 & 22.2 & $36.3 \pm 7.8$ & $34.4 \pm 4.2$ & 0.89 & $5.68 \pm 6.40$ & $5.54 \pm 5.10$ & 0.55 \\
\hline $\begin{array}{l}\bar{\Xi} \\
\vdots 0\end{array}$ & Sezon içi & 78.9 & 74.1 & $36.2 \pm 7.2$ & $36.8 \pm 7.7$ & 1.00 & $4.96 \pm 4.90$ & $5.23 \pm 2.30$ & 0.64 \\
\hline ถే & $\begin{array}{l}\text { Sezon } \\
\text { sonrası }\end{array}$ & 2.7 & 3.7 & $39.0 \pm 11.0$ & $37.1 \pm 2.7$ & 0.87 & $8.00 \pm 8.60$ & $7.56 \pm 4.20$ & 0.44 \\
\hline
\end{tabular}

Yaralanmanın geçirildiği bölgeye göre TKÖ değerleri araştırıldığında FTİ ve FTİM sporlarda gruplar arası anlamlı bir fark çıkmadı ( $p>0.05)$. Yaralanmanın geçirildiği bölgeye göre BDE skorları incelendiğinde, FTIM sporcularda FTI sporculara göre gövde yaralanmaları $(\mathrm{p}<0.05)$ ile ayak bileği ve omuz yaralanmalarında $(\mathrm{p}<0.001)$ BDE skorlarının istatistiksel olarak daha yüksek olduğu gözlenirken, diğer yaralanma bölgelerinde anlamlı fark belirlenmedi ( $p>0.05)$. Konulan tanıya göre FTİ ve FTİM sporlarda TKÖ ve BDE skorlarında anlamlı bir fark ortaya konmadı ( $p>0.05$ ) (Tablo 5).

\section{TARTIŞMA}

Spor dalı ne olursa olsun, her sporcu spor yaşamı boyunca küçük çaplı ya da ileri düzeyde spor yaralanmasına maruz kalmaktadır. Spor yaralanmalarının ilk dönemlerinde en sık gözlenen psikolojik problemin duygu durum bozukluğu olduğu yönündedir (1). Bir yaralanma sonrası fiziksel ve psikolojik olarak spora dönmeye hazırlık durumu her zaman yeterli düzeyde olmayabilir. Fiziksel bozukluklar ve belirtiler ortadan kalksa bile, kinezyofobi özgüveni azaltarak fiziksel bozuklukların iyileşmesini olumsuz yönde etkileyebilmekte ve spora başarılı dönüşü önleyebilmektedir (26). Ön çapraz bağ yaralanması, kronik bel ve boyun ağrısı gibi kronik yaralanmalarda sıklıkla kinezyofobi gözlenebilmektedir $(5,27,28)$. Ön çapraz bağ operasyonu sonrası spora başarılı şekilde dönemeyen sporcuların \%20-24'ünün kinezyofobi kaynaklı nedeni olduğu belirlenmiştir. Yaralanma öncesi performanslarına dönen sporcularda hareket nedenli tekrar sakatlanma korkusu daha azdır (11). Depresyonda olan bireyler ise yaralanma sonrası yıl boyunca yaralanma öncesi düzeylere geri dönememekte ve yaralanmaya bağlı bu psikolojik tepkiler, fonksiyonel bozukluklara neden olabilmektedir (29). Kas-iskelet sistemi ağrılarında kinezyofobi ile ağrı şiddeti, fonksiyonel kısitllık ve psikolojik özellikler arasında ilişki bulunmaktadır (30).Bu sonuçlardan farklı olarak servikal diskopatili 
hastalarda, psikolojik ve ağrı ile ilişkili klinik verilerin kinezyofobide belirleyiciler olmadığını belirten sonuçlar bulunmaktadır (28). $\mathrm{Bu}$ çalışmada da buna benzer olarak sporcularda kinezyofobinin depresyon düzeyleriyle ilişkili olmadığı anlaşılmıştır. $\mathrm{Bu}$ sonuçlara göre sporcuların TKÖ değerlerinin, depresyon dışındaki diğer faktörlerden etkilenebileceği düşünülebilir.

Tablo 5. Yaralanma bölgesine göre kinezyofobi, depresyon düzeyleri ve tanıya göre yüzdelik dağılım

\begin{tabular}{|c|c|c|c|c|c|c|c|c|}
\hline $\begin{array}{l}\text { Yaralanma } \\
\text { Bölgesi }\end{array}$ & $\mathbf{N}$ & $\%$ & $\begin{array}{l}\text { FTİ TKÖ } \\
\text { skorları }\end{array}$ & $\begin{array}{c}\text { FTiM TKÖ } \\
\text { skorları }\end{array}$ & p-değeri & $\begin{array}{l}\text { FTI BDE } \\
\text { skorları }\end{array}$ & $\begin{array}{l}\text { FTIMM BDE } \\
\text { skorları }\end{array}$ & p-değeri \\
\hline Ayak bileği & 48 & 36.9 & $36.0 \pm 7.67$ & $34.0 \pm 3.4$ & 0.21 & $4.37 \pm 9.43$ & $7.55 \pm 1.21$ & $0.001^{* *}$ \\
\hline Diz & 29 & 22.3 & $37.1 \pm 8.5$ & $39.2 \pm 2.1$ & 0.11 & $4.34 \pm 7.39$ & $5.25 \pm 4.41$ & 0.24 \\
\hline Omuz & 13 & 10.0 & $38.6 \pm 6.3$ & $37.1 \pm 3.3$ & 0.45 & $4.24 \pm 4.23$ & $6.78 \pm 1.83$ & $0.001^{* *}$ \\
\hline Kalça & 10 & 7.69 & $33.3 \pm 8.6$ & $36.8 \pm 4.3$ & 0.46 & $4.32 \pm 3.41$ & $4.21 \pm 2.38$ & 0.04 \\
\hline Dirsek & 8 & 6.15 & $37.4 \pm 5.2$ & $32.2 \pm 2.2$ & 0.55 & $9.83 \pm 9.64$ & $8.72 \pm 0.26$ & 0.25 \\
\hline Gövde & 7 & 5.38 & $40.3 \pm 7.2$ & $39.1 \pm 3.1$ & 0.15 & $6.12 \pm 9.31$ & $9.65 \pm 1.21$ & $0.004^{*}$ \\
\hline Baş/boyun & 2 & 1.53 & $38.0 \pm 14.1$ & $36.3 \pm 1.1$ & 0.61 & $4.31 \pm 4.39$ & $4.27 \pm 1.52$ & 0.19 \\
\hline El bileği & 2 & 1.53 & $41.0 \pm 1.4$ & $35.2 \pm 2.5$ & 0.82 & $4.15 \pm 3.03$ & $5.01 \pm 2.87$ & 0.20 \\
\hline Diğer & 11 & 8.46 & $33.8 \pm 5.1$ & $32.6 \pm 2.6$ & 0.30 & $4.02 \pm 3.01$ & $5.21 \pm 1.43$ & 0.31 \\
\hline Tanı & $\mathbf{N}$ & $\%$ & $\begin{array}{l}\text { FTİ TKÖ } \\
\text { skorları }\end{array}$ & $\begin{array}{c}\text { FTiM TKÖ } \\
\text { skorları }\end{array}$ & p-değeri & $\begin{array}{l}\text { FTİ BDE } \\
\text { skorları }\end{array}$ & $\begin{array}{c}\text { FTIM BDE } \\
\text { skorları }\end{array}$ & p-değeri \\
\hline Burkulma & 41 & 31.5 & $36.3 \pm 7.7$ & $32.3 \pm 3.7$ & 0.421 & $5.27 \pm 1.39$ & $5.27 \pm 1.52$ & 0.01 \\
\hline $\begin{array}{l}\text { Ligament } \\
\text { yaralanması }\end{array}$ & 33 & 25.4 & $36.9 \pm 6.3$ & $34.5 \pm 2.1$ & 0.15 & $4.27 \pm 4.23$ & $5.17 \pm 2.09$ & 0.31 \\
\hline Kas yırtığı & 18 & 13.9 & $33.8 \pm 4.6$ & $32.8 \pm 2.1$ & 0.50 & $4.53 \pm 3.41$ & $4.21 \pm 2.38$ & 0.21 \\
\hline $\begin{array}{l}\text { Yumuşak doku } \\
\text { yaralanması }\end{array}$ & 11 & 8.5 & $35.7 \pm 5.7$ & $31.3 \pm 1.7$ & 0.31 & $5.98 \pm 2.09$ & $4.07 \pm 3.51$ & 0.15 \\
\hline Kırık & 10 & 7.7 & $34.7 \pm 8.3$ & $33.8 \pm 2.2$ & 0.91 & $4.32 \pm 1.01$ & $5.43 \pm 2.76$ & 0.40 \\
\hline $\begin{array}{l}\text { Menisküs } \\
\text { dejenerasyonu }\end{array}$ & 5 & 3.8 & $36.8 \pm 7.7$ & $31.8 \pm 7.6$ & 0.08 & $5.93 \pm 3.21$ & $4.54 \pm 2.12$ & 0.62 \\
\hline Yara/kesik & 5 & 3.8 & $36.8 \pm 9.7$ & $34.8 \pm 2.4$ & 0.13 & $4.12 \pm 0.19$ & $4.15 \pm 2.01$ & 0.10 \\
\hline Çatlak & 4 & 3.1 & $43.7 \pm 0.6$ & $40.2 \pm 0.5$ & 0.10 & $4.74 \pm 2.73$ & $5.75 \pm 1.87$ & 0.05 \\
\hline Çıkık & 3 & 2.3 & $31.0 \pm 12.7$ & $32.3 \pm 11.4$ & 0.41 & $5.12 \pm 3.01$ & $4.11 \pm 2.67$ & 0.09 \\
\hline
\end{tabular}

FTİ: Fiziksel Temas İçeren, FTIM: Fiziksel Temas İçermeyen, TKÖ: Tampa Kinezyofobi Ölçeği, BDE: Beck Depresyon Ölçeği Değerler ortalama \pm standart sapmadır. İstatistiksel anlamlılık düzeyi $\mathrm{p}<0.05$ anlamlı kabul edilmiştir. ${ }^{*} \mathrm{p}<0.05{ }^{* *} \mathrm{p}<0.001$.

Psikolojik faktörlerden sadece müsabaka kaygısının spor yaralanmasında etkili olduğunu, genel kaygının (anksiyete) ise bu yaralanmalarda etkisinin olmadı̆̆ını belirten çalışmalar bulunmaktadır (31). Benlik algısı, öfke ifade tarzı, A tipi kişilik, özsaygı, günlük problemler, bedensel tükenme, kişilerarası tarz, dikkat, yorgunluk, benlik kavramı, reaksiyon süresi gibi psikolojik özelliklerin spor yaralanmalarına etkileri üzerine yapılan çalışma sonuçları net olmayıp kısmen çelişkilidir (31). Sporcularda yaşam olaylarının spor yaralanmalarına neden olabileceği; sosyal desteğin ise buna pozitif etkisi olduğu belirtilmektedir. Araştırmalar evlilik, boşanma, iş değişikliği gibi yaşamlardaki stresli değişikliklerin depresyon gibi psikolojik rahatsızlıklara neden olduğunu ve spor yaralanma riskini arttırdığını; stresli yaşam değişiklikleri nedenli yaralanmaların FTİ ve FTIM sporlarda değişkenlik gösterebileceğini belirtmektedir (32).

Brewer ve ark. yaptıkları çalışmaya göre spor yaralanması geçiren sporcuların sadece \%4.8'inin klinik düzeyde depresyon skoruna (BDE skoru>16) sahip olduklarını ve bu oranın 
genel nüfusta \%5.7 olduğunu belirtmişlerdir (33). Manuel ve ark. spor yaralanması geçiren gençlerin \%27'sinin yaralanmadan hemen sonra orta düzeyde depresyon (BDE skoru>15) yaşadıklarını ve bu değerlerin zaman geçtikçe düşüş sergilediğini; 3 . haftada bu oranın $\% 21$ 'e, 6. haftada \%17'ye ve 12 . haftada ise \%13'e gerilediğini ortaya koymuşlardır (34). Bundan farklı olarak, Leddy ve ark. spor yaralanması geçiren sporcularda yaralanmadan hemen sonra ve iki ay sonra kontrol grubuna göre daha yüksek oranda depresyon görüldüğü sonucunu ortaya koymuşlardır (35). Hutchison ve ark. ise spor yaralanmasindan hemen sonra depresyon düzeylerinde anlamlı olmasa da artış gözlendiğini ve iki hafta süresince devam ettiğini belirtmișlerdir (36). Appaneal ve ark. spor yaralanmasından bir hafta sonra "Hamilton Depresyon Skalası" ile değerlendirilen depresyon düzeylerinin artış gösterdiğini ve bir ay kadar devam ettiğini, fakat "Epidemiyolojik Araștırmalar Merkezi Depresyon Skalası" değerlendirmesine göre ise kontrol grubu ile fark olmadığını ortaya koymuşlardır (4). Bu sonuçlara göre yaralanmanın erken dönemlerinde sporcularda depresyon bulguları görülse bile zamanla bu psikolojik etkilerin azaldığı söylenebilir (36,37). Çalışmamızda sporcularda yaralanma sonrası klinik depresyon düzeyleri (BDE skoru >16) gözlenmedi. Sporcuların geriye dönük beyanlarıyla yapılan değerlendirme ile depresyon saptanmamasının Hutchison ve ark.nın (36) ve Brewer ve Petrie'nin (37) de belirttikleri gibi, depresyon skorlarının zamanla azalma eğilimi göstermesinden kaynaklandığı düşünülebilir.

Çalışmada aktivite türlerine göre antrenman ve müsabaka sirasinda meydana gelen yaralanmalarda, depresyon skorlarının klinik düzeye erişmese de FTİ sporlarda FTIMM sporlara oranla istatistiksel olarak daha yüksek olduğu belirlendi. Bazı araștırmacılar, sporcuların yaralanma sonrası depresif semptomlarını hızlandiran nedenlerin yaralanmandan daha ziyade, spordan uzak kalmaya bağlı sportif rekabette geri düşme kaygısı yaşamalarından kaynaklanabileceğini savunmaktadırlar (38). Çoğunluğu takım sporu olan FTİ sporlarda yaralanmanın yanı sıra takımdan uzak kalmaya bağlı sportif rekabette geri düșme kaygısı ortaya çıkabilir. BDE skorlarının FTİ sporlarda FTIM sporlara göre daha yüksek bulunması bu kaygıyla açıklanabilir.

Erkek sporcularda futbol, güreş ve atletizm yaralanmalarının üçte ikisi antrenman sırasında meydana gelmektedir. Bunun nedeni olarak da bu sporlarda antrenmanda harcanan sürelerin müsabakada harcanan sürelerden daha fazla olması öne sürülmektedir (17). Bu görüşe koşut olarak, çalışmamızda antrenman sırasında meydana gelen yaralanma oranları FTİ ve FTIMM sporlar için sırasıyla \%52.3 ve \%75.9 olarak bulunmuş iken, müsabaka sırasında meydana gelen yaralanma oranları sirasıyla $\% 47.7$ ve $\% 24.1$ idi $(\mathrm{p}<0.05)$. Futbol, güreș, basketbol, beyzbol, atletizm gibi sporlarda antrenmanlarda meydana gelen yaralanmaların müsabakada meydana gelenlere kıyasla daha fazla olmasının bir diğer nedeninin de, daha uzun antrenman süreleri boyunca daha fazla fiziksel temasın meydana gelmesi kaynaklı olabileceği sonucu çıkarılabilir.

Walker, spor yaralanmalarının sezon başlarında daha sık görüldüğünü, örneğin futbolda ayak bileği yaralanmalarının \%44'ünün sezonun ilk üç ayı içerisinde meydana geldiğini belirtmiştir (39). Futbol gibi fiziksel temas içeren sporlarda akut travmatik yaralanmalar oransal olarak daha yüksek gerçekleşirken, atletizm gibi fiziksel temas içermeyen sporlarda ise aşırı kullanım yaralanmaları daha sık görülmektedir (40). Çalışmamızda buna benzer şekilde sezon içi yaralanma oranları FTI ve FTIM sporlarda sırasıyla \%79 ve \%74 çıtı. Sezon öncesi ise bu oranlar sirasiyla $\% 18$ ve $\% 22$ idi.

$\mathrm{Bu}$ sonuçlara ek olarak, spor yaralanmalarıyla kinezyofobi ve depresyon ilişkisi izleme niteliğindeki çalışmalarla sporcularda yaralanma sonrası kinezyofobinin nedenleri belirlenerek literatüre katkı sağlanabilir. İleride yapılacak çalışmalarla hekimler, fizyoterapistler ve spor profesyonelleri yaralanma sonrası rehabilitasyon sürecinde kinezyofobi ve benzer psikolojik faktörlere uygun stratejiler geliştirebilirler.

\section{SONUÇ}


Bu çalışmada, fiziksel temas içeren ve içermeyen sporlarda, yaralanma sonrası gözlenen kinezyofobi ve depresyonun ilişkisi incelendi. Spor yaralanmaları sonrasinda, depresyon ve kinezyofobi skorları açısından FTI ve FTIM sporlar arasında fark olmadı $\breve{~} ı$ belirlendi. Kinezyofobinin sporcuların duygu durumlarıyla

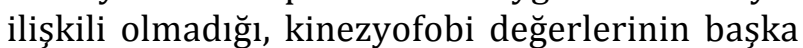
faktörlerden etkilenebileceği söylenebilir. Sporcuların rehabilitasyon programlarında kinezyofobi ve depresyon durumunun daha fazla dikkate alınması, rehabilitasyon süreçlerine olumlu katkı sağlayabilir.

\section{KAYNAKLAR}

1. Smith AM. Psychological impact of injuries in athletes. Sports Med. 1996;22:391-405.

2. Johnston LH, Carroll D. The context of emotional responses to athletic injury: a qualitative analysis. $J$ Sport Rehabil. 1998;7:206-20.

3. Tracey J. The emotional response to the injury and rehabilitation process. J Appl Sport Psychol. 2003;15: 279-93.

4. Appaneal RN, Levine BR, Perna FM, et al. Measuring post injury depression among male and female competitive athletes. J Sport Exerc Psychol. 2009;31: 60-76.

5. Ardern CL, Webster KE, Taylor NF, et al. Return to sport following anterior cruciate ligament reconstruction surgery: A systematic review and meta-analysis of the state of play. Br J Sports Med. 2011;45:596-606.

6. Ardern CL, Taylor NF, Feller JA, et al. A systematic review of the psychological factors associated with returning to sport following injury. Br J Sports Med. 2013;47:1120-6.

7. Leeuw M, Goossens ME, Linton SJ, et al. The fearavoidance model of musculoskeletal pain: Current state of scientific evidence. J Behav Med. 2007;30:77-94.

8. Meier ML, Stämpfli P, Vrana A, et al. Neural correlates of fear of movement in patients with chronic low back pain vs. pain-free individuals. Front Hum Neurosci. 2016;10:386.

9. Riccio A, Li Y, Moon J, et al. Essential role for TRPC5 in amygdala function and fear-related behavior. Cell. 2009;137:761-72.

10. Kori SH, Miller RP, Todd DD. Kinesiophobia: a new view of chronic pain behavior. Pain Manag. 1990;3:35-43.

11. Kvist J, Ek A, Sporrstedt K, et al. Fear of re-injury: a hindrance for returning to sports after anterior cruciate ligament reconstruction. Knee Surg Sports Traumatol Arthrosc. 2005;13:393-7.

12. Podlog L, Eklund RC. Return to sport after serious injury: a retrospective examination of motivation and psychological outcomes. J Sport Rehabil. 2005;14:20-34.
13. Gissane C, White J, Kerr K, et al. An operational model to investigate contact sports injuries. Med Sci Sports Exerc. 2001;33:1999-2003.

14. Bahr R, Holme I. Risk factors for sports injuries - a methodological approach. Br J Sports Med. 2003;37: 384-392.

15. Shephard RJ. Can we afford to exercise, given current injury rates? Inj Prev. 2003;9:99-100.

16. Maffulli N, Baxter-Jones ADG, Grieve A. Long term sportinvolvement and sport injury rate in elite young athletes. Arch Dis Child. 2005;90:525-7.

17. Kraus JF, Conroy C. Mortality and morbidity from injuries in sports and recreation. Annu Rev Public Health. 1984;5:163-92.

18. Heijne A, Axelsson K, Werner S, et al. Rehabilitation andrecovery after anterior cruciate ligament reconstruction: Patients' experiences. Scand J Med Sci Sports. 2008;18: 325-35.

19. Rice SG, American Academy of Pediatrics Council on Sports Medicine and Fitness. Medical conditions affecting sports participation. Pediatrics. 2008;121:841-8.

20. Lanese RR, Strauss RH, Leizman DJ, et al. Injury and disability in matched men's and women's intercollegiate sports. Am J Public Health. 1990;80:1459-62.

21. Bränström H, Fahlström M. Kinesiophobia in patients with chronic musculoskeletal pain: differences between men and women. J Rehabil Med. 2008;40:375-80.

22. Vlaeyen JW, Linton SJ. Fear-avoidance and its consequences in chronic musculoskeletal pain: a state of the art. Pain. 2000;85:317-32.

23. Yllmaz ÖT, Yakut Y, Uygur F, et al. Tampa kinezyofobi ölçeğinin Türkçe versiyonu ve test tekrar test güvenirliği. Fizyoterapi Rehabilitasyon. 2011;22:44-9.

24. Vlaeyen JW, Kole-Snijders AM, Boeren RG, et al. Fear of movement/(re) injury in chronic low back pain and its relation to behavioral performance. Pain. 1995;62: 363-72.

25. Hisli N. Beck Depresyon Envanterinin geçerliği üzerine bir çalışma. Psikoloji Dergisi. 1988;6:118-22.

26. Hsu CJ, Meierbachtol A, George SZ, et al. Fear of reinjury in athletes: implications for rehabilitation. Sports Health. 2017;9:162-7.

27. Grotle M, Vøllestad NK, Brox JI. Clinical course and impact of fear-avoidance beliefs in low back pain: prospective cohort study of acute and chronic low back pain: II. Spine. 2006;31:1038-46.

28. Misterska E, Jankowski R, Głowacki J, et al. Kinesiophobia in pre-operative patients with cervical discopathy and coexisting degenerative changes in relation to painrelated variables, psychological state and sports activity. Med Sci Monit. 2015;21:181-94.

29. Richmond TS, Amsterdam JD, Guo W, et al. The effect of post-injury depression on return to pre-injury function: a prospective cohort study. Psychol Med. 2009;39:1709-20. 
30. Lundberg MK. Various aspects of moving with musculoskeletal pain. PhD thesis, Department of Orthopaedics, Institute of Clinical Sciences. The Sahlgrenska Academy at Göteborg University, Göteborg. p.1-126; 2006.

31. Junge A. The influence of psychological factors on sports injuries. Am J Sports Med. 2000;28:10-5.

32. Kerr G, Fowler B. The relationship between psychological factors and sports injuries. Sports Med. 1988;6:127-34.

33. Brewer BW, Linder DE, Phelps CM. Situational correlates of emotional adjustment to athletic injury. Clin J Sport Med. 1995;5:241-5.

34. Manuel JC, Shilt JS, Curl WW, et al. Coping with sports injuries: an examination of the adolescent athlete. $J$ Adolesc Health. 2002;31:391-3.

35. Leddy MH, Lambert MJ, Ogles BM. Psychological consequences of athletic injury among high-level competitors. Res Q Exerc Sport. 1994;65:347-54.
36. Hutchison M, Mainwaring LM, Comper P, et al. Differential emotional responses of varsity athletes to concussion and musculoskeletal injuries. Clin J Sport Med. 2009; 19:13-9.

37. Brewer BW, Petrie TA. A comparison between injured and uninjured football players on selected psychosocial variables. J Athl Train. 1995;10:11-8.

38. Chan CS, Grossman HY. Psychological effects of runningloss on consistent runners. Percept Mot Skills. 1988;66: 875-83.

39. Walker I. Soccer injuries-ankle sprains: the bane of soccer players. J Sports Med. 2003;37:233-8.

40. Armsey TD, Hosey RG. Medical aspects of sports: Epidemiology of injuries, preparticipation physical examination, and drugs in sports. Clin Sports Med. 2004;23:255-79. 